\title{
HCV AND DRUG ABUSERS - morphological changes (Liver biopsy in CHC and heroin abuse)
}

Desislava Lubomirova ${ }^{1}$, Ivanka Marinova ${ }^{1}$, Reni Ivanova ${ }^{2}$, Ivan Ivanov ${ }^{2}$, Angelika Velkova ${ }^{3}$, Kaloian Stoychev ${ }^{4}$, Ivan Lalev $^{1}$, Radina Ivanova ${ }^{5}$, Pavlina lordanova - Laleva ${ }^{6}$, Zaharinka Sabeva $^{1}$, Margarita Vlahova ${ }^{1}$

1. Department of nephrology, hematology and gastroenterology, Medical University, Pleven; Clinic of gastroenterology, University Hospital "Dr G. Stranski" Pleven;

2. Department of general and clinical pathology, Medical University, Pleven; University Hospital "Dr G. Stranski" Pleven

3. Department of Social medicine, Medical UniversitySofia;

4. Department of psychiatry and medical psychology, Medical University, Pleven; Second Pcychiatric Clinic, University Hospital "Dr G. Stranski" Pleven;

5. Laboratory of clinical pathology, University Hospital "St. I. Rilski", Medical University, Sofia;

6. Faculty of Pharmacy, Medical University, Pleven; Department of Clinical laboratory, University Hospital "Dr Georgi Stranski" Pleven; 


\begin{abstract}
The aim of the study was to evaluate the morphological changes in the liver biopsies from patients with chronic hepatitis $\mathrm{C}(\mathrm{CHC})$ and heroin abuse (HA). Material and methods: In the study were included 10

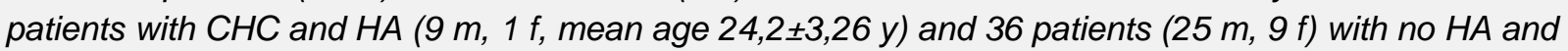

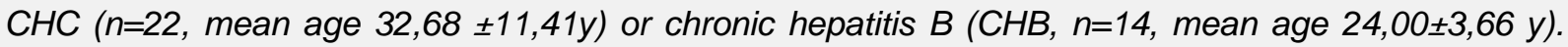
The diagnosis of chronic hepatitis was put according to standard criteria and liver biopsy was done in all cases. The grading of activity and staging of fibrosis by METAVIR, the presence of steatosis and depletion of glycogen content was evaluated after using HE, V. Gieson, Gomori and PAS stains. Results: In the group of HA patients with $\mathrm{CHC}$ were found more often moderate grade of inflammation (A2, 60\%) and clinically significant stage of fibrosis (F2, 70\%) while in the both groups of non- HA patients with $\mathrm{CHC}$ or $\mathrm{CHB}$ the prevalences of mild grade of activity (A1,59\% and 50\%, respectively) and early stage of fibrosis ( $F 1,59 \%$ and $71 \%$ ) were predominant. No significant differences were found in the comparison of HA patients with $\mathrm{CHC}$ and non- $\mathrm{HA}$ control groups regarding the presence of steatosis and decrease of glycogen contents in hepatocytes. In conclusion, our study showed that in liver biopsies of patients with $\mathrm{CHC}$ and heroin abuse there were more severe morphological changes including grading and staging of chronic hepatitis compared to the cases with $\mathrm{CHC}$ or $\mathrm{CHB}$ without history of drug abuse.
\end{abstract}

Keywords: liver biopsy, chronic hepatitis C, heroin abuse.

\title{
Introduction
}

It is well known that the addiction to heroin is related to a lot of short-term and long-term effects on the health of drug abusers. The main part of the long-term effects are related with the use of contaminated heroin, infected needles, syringes, spoons (1-17). The heroin addicted subjects are the main risk group for infection with hepatitis $\mathrm{C}$ virus ( $\mathrm{HCV})$. In literature various pathological changes in the livers of heroin abusers have been reported (18-22). They included quantitative and qualitative alterations of cellular organelles, extracellular matrix and hepatic vascular system like vacuole and fatty degeneration, changes in the cellular nucleus, membranes or intracellular content of glycogen, inflammation, fibrosis/cirrhosis, dysplasia, amyloidosis. All of them can be resulted by the HCV infection, heroin itself, and also by concomitant alcohol abuse, if present. In addition, the intensity of liver morphological changes is related to the duration of misuse. The aim of our study was to evaluate the morphological changes in the liver biopsies from heroin addicted patients with chronic hepatitis $C$.

\section{Materials and methods}

In the study were included 10 patients with chronic hepatitis $\mathrm{C}(\mathrm{CHC})$ and heroin abuse $(\mathrm{HA})$ and 36 patients with no evidence of addiction to any psychoactive substances and $\mathrm{CHC}(n=22)$ or chronic hepatitis $\mathrm{B}(\mathrm{CHB}, \mathrm{n}=14)$ as controls. The diagnosis of chronic hepatitis was put according to standard criteria and liver biopsy was done in all cases. The morphological changes in liver samples were investigated through different scoring systems, after routine processing and haematoxilline-eosine (HE), 
van Gieson and Gomori stainings for fibrosis, as well as PAS (Periodic Acid Schiff) stain for carbohydrates/glycogen (23-25). The severity of inflammation and stage of fibrosis were defined according to METAVIR, and also the presence or no of steatosis. The decrease in hepatocytes glycogen content using PAS staining was evaluated semiquantitatively into 4 grades as follows: 0 - no decrease, grade 1 mild, grade 2 - moderate and grade 3 -severe glycogen decrease in hepatocytes.

\section{Results}

Demographic characteristics of the patients with and no HA and chronic hepatitis In the group of patients with $\mathrm{CHC}$ and $\mathrm{HA}, 9$ cases $(90 \%)$ were males and only $1(10 \%)$-female. Among all cases with no HA and $\mathrm{CHC}$ or CHB $(n=36), 25(69 \%)$ were males and the rest 9 cases $(31 \%)$ - females. There was no significant difference by sex in comparison the cases with and no $\mathrm{HA}$ and chronic hepatitis. The mean age of HA patients with $\mathrm{CHC}$ was significantly lower compared to the cases with no $\mathrm{HA}$ and $\mathrm{CHC}(\mathrm{t}=5,246$; $\mathrm{p}=0,029$ ) (tabl. 1). There was no difference between the mean ages of the patients with $\mathrm{CHC}$ and $\mathrm{HA}$ and those with $\mathrm{CHB}$ without $\mathrm{HA}$. The average duration of the heroin abuse in cases with $\mathrm{CHC}$ was $6.00 \pm 1,83$ years (from 3 to 8 yrs) as in 7 of them the duration of heroin abuse was above 5 years.

Table1. Mean age of the HA patients with $\mathrm{CHC}$ and control groups of cases with $\mathrm{CHC}$ and CHB.

\begin{tabular}{|c|c|c|c|c|}
\hline groups & Mean & SD & Min. & Max. \\
\hline HA patients with $\mathrm{CHC}$ & 24,20 & $\pm 3,26$ & 18,00 & 31,00 \\
\hline Patients with $\mathrm{CHC}$ without drugs & 32,68 & $\pm 11,41$ & 19,00 & 57,00 \\
\hline Patients with $\mathrm{CHB}$ without drugs & 24,00 & $\pm 3,66$ & 18,00 & 31,00 \\
\hline
\end{tabular}

\section{Liver morphological changes in the patients with and no HA and chronic hepatitis}

The histological grades of activity and stages of fibrosis using METAVIR in all studied patients are presented on table 2 and fig. 1-3. Among the HA patients and $\mathrm{CHC}$, the moderate degree of activity (A2) was the most common ( $n=6,60 \%)$, following by the mild grade $A 1$ (in 3 cases, $30 \%$ ) and severe grade $A 3$ (in 1 case, 10\%). In the both groups of cases with no HA, the portions of cases with mild degree of inflammation (A1) were the biggest (59\% and $50 \%$ for $\mathrm{CHC}$ and $\mathrm{CHB}$, respectively), following by that of moderate degree (32\% and $29 \%$ for $\mathrm{CHC}$ and $\mathrm{CHB}$, respectively) and severe grade (A3) was found in 2 and 1 cases with $\mathrm{CHC}$ and $\mathrm{CHB}$, respectively. Among the patients with $\mathrm{HA}$, the F2 stage was the most common (in 7 cases, $70 \%$ ), following by the F1 stage (in 2 cases, 20\%). 
Table 2. Distribution of grades of activity and stages of fibrosis by METAVIR in the cases with and no $\mathrm{HA}$ and chronic hepatitis.

\begin{tabular}{|c|c|c|c|c|}
\hline $\begin{array}{l}\text { Evaluation } \\
\text { according } \\
\text { METAVIR }\end{array}$ & $\begin{array}{l}\text { HA patients } \\
\text { with } \mathrm{CHC} \\
\text { (n) }\end{array}$ & $\begin{array}{lr}\text { Patients } & \text { with } \\
\mathrm{CHC} & \text { without } \\
\text { drugs } & \\
\text { (n) } & \end{array}$ & $\begin{array}{lr}\text { Patients } & \text { with } \\
\text { CHB } & \text { without } \\
\text { drugs } \\
\text { (n) }\end{array}$ & $\begin{array}{l}\text { Total } \\
\text { (n) }\end{array}$ \\
\hline AOF2 & 0 & 0 & 1 & 1 \\
\hline A1F0 & 0 & 1 & 1 & 2 \\
\hline A1F1 & 0 & 9 & 6 & 15 \\
\hline A1F2 & 3 & 3 & 1 & 7 \\
\hline $\mathrm{A} 2 \mathrm{FO}$ & 1 & 1 & 0 & 2 \\
\hline A2F1 & 2 & 1 & 3 & 6 \\
\hline A2F2 & 3 & 4 & 1 & 8 \\
\hline A2F3 & 0 & 1 & 0 & 1 \\
\hline A3F0 & 0 & 1 & 0 & 1 \\
\hline A3F1 & 0 & 1 & 1 & 2 \\
\hline A3F2 & 1 & 0 & 0 & 1 \\
\hline Total & 10 & 22 & 14 & 46 \\
\hline
\end{tabular}

There was no case with advanced fibrosis (F3 or F4). On the opposite, among the cases with no HA and $\mathrm{CHC}$ or $\mathrm{CHB}$, the prevalence of $\mathrm{F} 1$ stage was the highest ( $59 \%$ and $71 \%$ for $\mathrm{CHC}$ and $\mathrm{CHB}$, respectively), following by that of $\mathrm{F} 2$ stage ( $32 \%$ and $21 \%$ for $\mathrm{CHC}$ and $\mathrm{CHB}$, respectively). Only one case with $\mathrm{F} 3$ stage was found, from the group of cases with no $\mathrm{HA}$ and $\mathrm{CHC}$. 


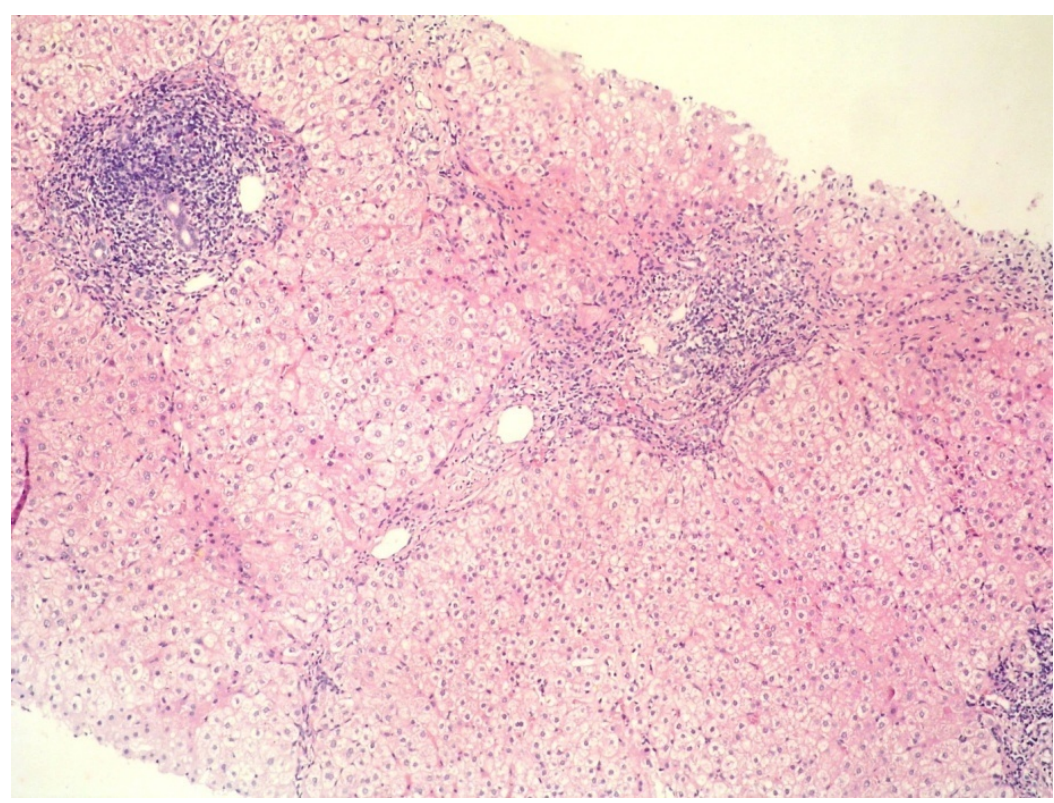

Figure 1. CHC without heroin abuse. Enlarged periportal spaces with marked round cell infiltrates with formation of lymphoid follicules, piece meal necrosis and mild fibrosis. HE, x 100.

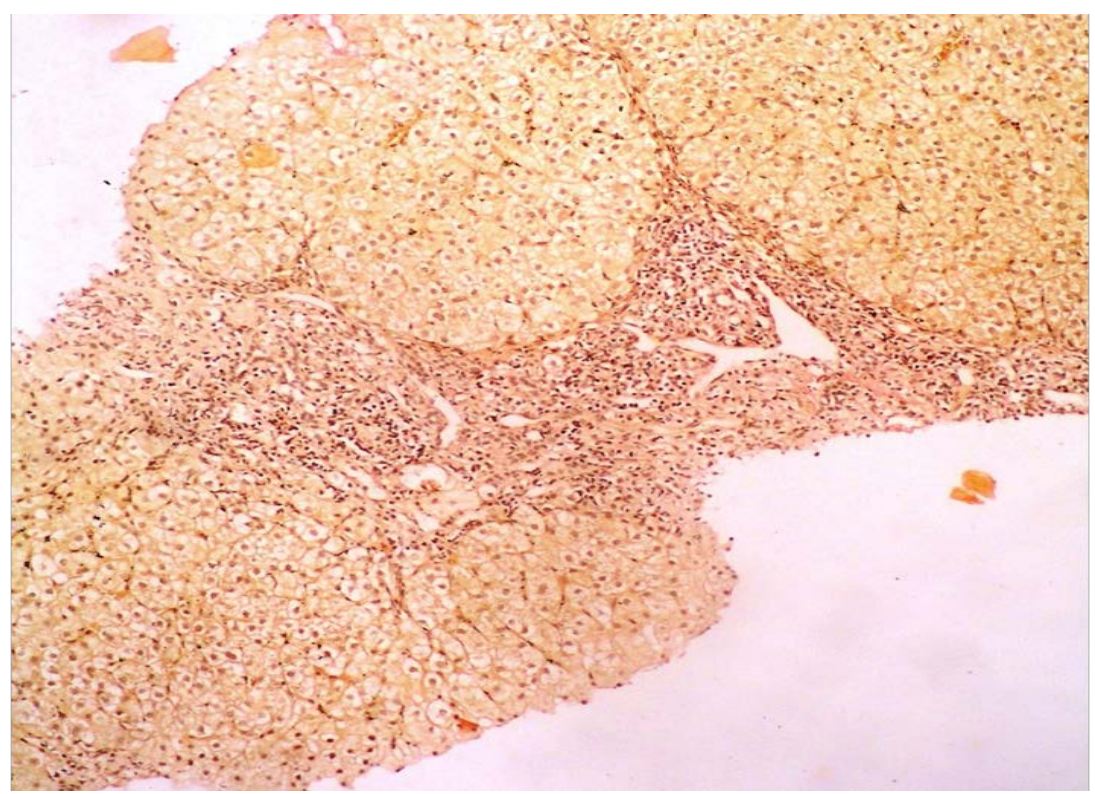

Figure 2. $\mathrm{CHC}$ and heroin abuse. There is moderate fibrosis in the enlarged periportal space, piece meal necrosis and mild pericentral fibrosis. The collagen fibres are stained in pink / light red. Van Gieson staining, $x 100$ 


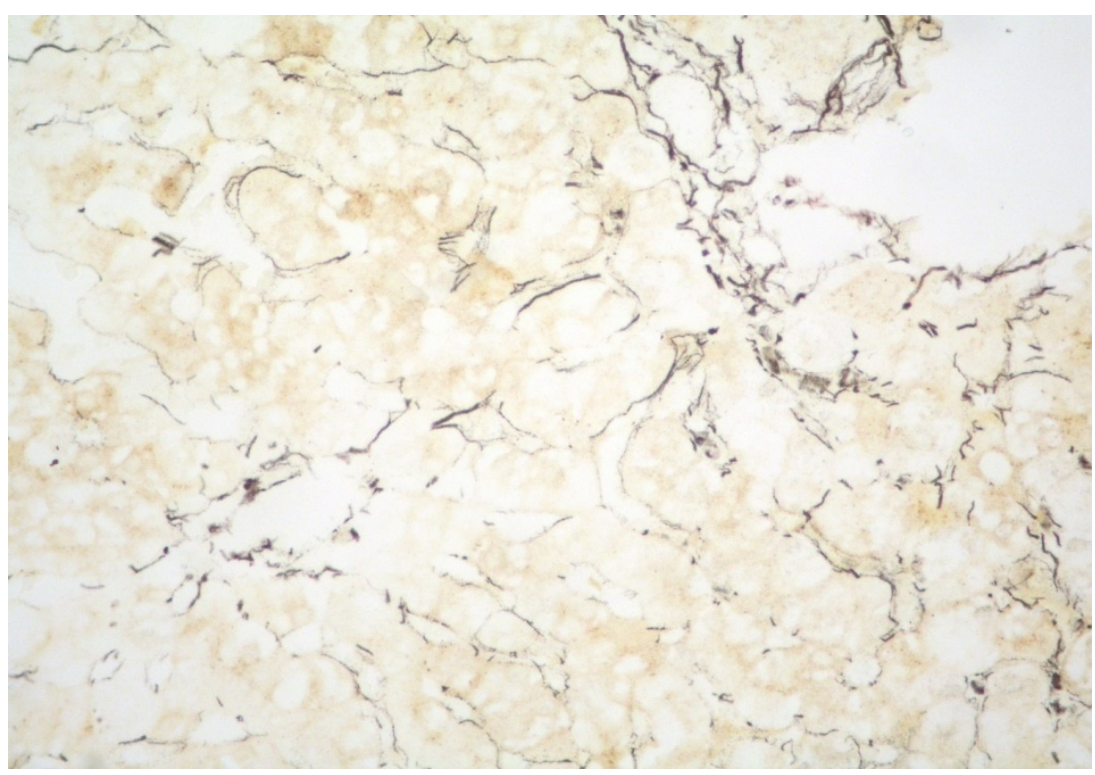

Figure 3. $\mathrm{CHC}$ and heroin abuse. A liver lobule, in which discrete reticular fibres (stained dark brownish to black) are seen. Gomori staining, $x 400$.

In addition, we performed comparative analysis of histological grades of activity and stages of fibrosis among the HA cases with $\mathrm{CHC}$ according to the duration of heroin abuse ( $>$ and $<5 \mathrm{y}$ ). We found that in cases with shorter duration of heroin abuse $(n=3)$ the morphological changes tend to be milder regarding inflammation and fibrosis compared to the cases with duration of heroin addiction $>5$ years.

We found no difference in the presence of steatosis between the HA cases with $\mathrm{CHC}$ and control groups. But steatosis was observed in four from the $7 \mathrm{HA}$ patients and $\mathrm{CHC}$ with more than 5 years duration of the abuse and in no one with shorter duration of heroin addiction.

Using PAS staining, in the majority of HA patients with $\mathrm{CHC}$ mild to moderate grades of decreased glycogen content in the hepatocytes were found but without significant difference in comparison with control groups of cases (fig. 4). 


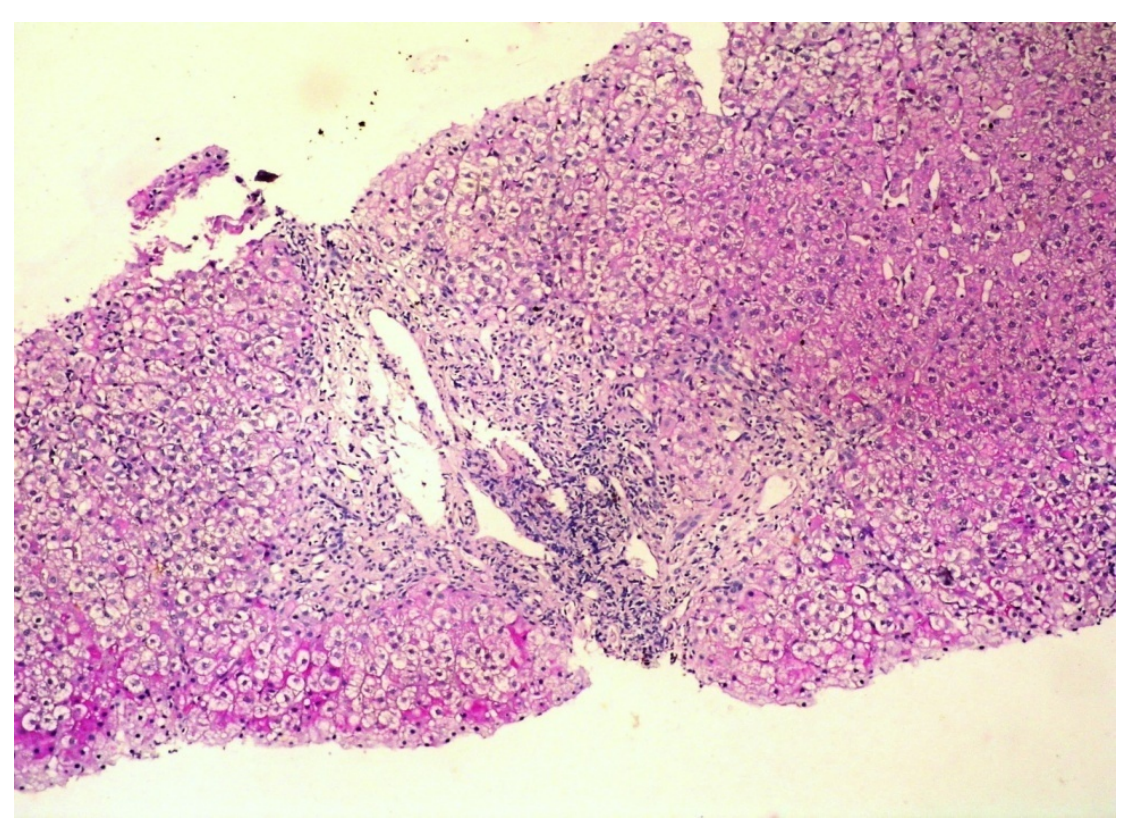

Figure 4. CHC and heroin abuse. Enlarged periportal spaces with moderately presented round cell infiltrates, piece meal necrosis. In the cytoplasm of small part of the hepatocites pink stained (PAS positive) glycogen content is observed (sign of deminished glycogen content). PAS staining, $x$ 100.

\section{Discussion}

The liver biopsy is the gold standard for evaluation the severity of liver damage in patients with chronic liver diseases. Beside grading of activity and staging of fibrosis, it gives opportunity to assess other features, which also have clinical significance. In this study we aimed to evaluate the morphological changes in liver biopsies from heroin addicted patients with $\mathrm{CHC}$ and to compare with those in cases with $\mathrm{CHC}$ and $\mathrm{CHB}$ without history for addiction to any drugs. Our small group of HA cases with $\mathrm{CHC}$ included mostly very young males with mean duration of heroin misuse of 6 years. The mean age of the studied cases was similar to that of control cases with $\mathrm{CHB}$, but significantly lower in comparison with the mean age of non-HA with $\mathrm{CHC}$. The young age of our HA patients with $\mathrm{CHC}$ confirms that heroin addiction is strong risk factor for hepatitis $C$ virus infection. The evaluation of severity of liver damage using METAVIR showed some substantial differences between the HA cases with $\mathrm{CHC}$ and control cases with $\mathrm{CHC}$ and $\mathrm{CHB}$. Regarding the grading of activity, in over half of the HA patients we found moderate inflammation while in the both control groups of non-HA patients the mild inflammation predominated. About the staging of fibrosis, we found that all studied HA and non-HA patients with chronic hepatitis, except one from the control group with $\mathrm{CHC}$ have no severe fibrosis or cirrhosis. Nevertheless, among the HA cases with $\mathrm{CHC}$ the clinically significant stage $\mathrm{F} 2$ was established more often in comparison with the both groups of non-HA cases with $\mathrm{CHC}$ or CHB. In the last the early stage of fibrosis the early stage of fibrosis (F1) was found to be more common. There were no peculiar differences when compared the liver biopsies of the $\mathrm{HA} \mathrm{CHC}$ patients and non- $\mathrm{HA} \mathrm{CHC}$ or $\mathrm{CHB}$ cases concerning the presence or no of steatosis and the 
depletion of glycogen content in the hepatocytes, evaluated by PAS staining. When compared the severity of liver damage according to the duration of heroin misuse, we found that in cases with duration of heroin abuse less than 5 years the morphological changes tend to be milder regarding inflammation and fibrosis compared to those with longer duration of heroin abuse. The literature data for the morphological changes and severity of liver damage in HA patients with $\mathrm{CHC}$ on liver biopsies are scanty. In contrast, in several studies the light microscopic and ultrastructural changes in liver autopsy samples of intravenous heroin addicts have been reported (18-22). The authors summarized that heroin abuse induces significant morphologic changes in the liver tissue, including vesicular and fatty changes, reduction in the amount of glycogen in hepatocytes, chronic hepatitis, cirrhosis and the severity of these changes increases with years of heroin abuse.

In conclusion, our study showed that by the patients with $\mathrm{CHC}$ and heroin abuse the morphological changes, found in the liver biopsies including grading and staging of chronic hepatitis were similar to the ones, found by the cases with $\mathrm{CHC}$ or $\mathrm{CHB}$ without history of drug abuse, who were significantly older. Thus this could be the basis for establishing a group of patients with specific behavior problems and chronic liver diseases in the future. Further studies are needed to clarify the influence of heroin abuse on the severity of liver damage in chronic hepatitis $C$ and to estimate the future chronic disease burden for the society.

Acknowledgement: This publication was funded by Project BG05M2OP001-2.009-0031-C01.

\section{References}

1. Krastev Z. Chronic hepatitis. In: Hepatology, Publisher Tilia, 1998, pp 298-313. (in Bulgarian):

2. Krustev N. Chronic hepatitis C. In: Clinical Hepatology. 2008. p. 52-80. [In Bulgarian]. ISBN 978954-8932-47-9

3. Hickmann M, Carnath Z, Madden $\mathrm{P}$ et al. Drug related mortality and fatal overdose risk: pilot cohort study of heroin users recruited from specialist drug treatment sites in London. Journal of urban health: bulletin of the New York Academy of Medicine, 2003; 80: 274-287.

4. Le Moal M, Koob GF. Drug addiction: Pathways to the disease and pathophysiological perspectives. Eur. Neuropsychopharmacology. 2007; 17:377-393.

5. Bevan G. Problem drug use the health imperative: what some of the literature says. Subst Abuse Treat prev Poicy. 2009; 4: 21.

6. "Yellow List: List of Narcotic Drugs Under International Control".International Narcotics Control Board. Annex to Forms A, B and C, 50th edition, December 2011.

7. Healthcare Access and Quality Index based on mortality from causes amenable to personal health care in 195 countries and territories, 1990-2015: a novel analysis from the Global Burden of Disease Study 2015. Lancet, 390 (10091): 231-266.

8. HCV Guidance: Recommendations for testing, managing and treating hepatitis C. Last updated Sept. 21st, 2017. www.hcvguidlines.org.

9. EASL Recommendations on Treatment of Hepatitis C. J Hepatol (2016), http://dx.doi.org/10.1016/i.jhep.2016.09.001.

10. 10. Dandri M, Petersen J. HCV virology. // Hepatology.A clinical textbook. 5th edition. Ed. Mauss S. Berg T, Rockstroh J., Sarrazin C, Wedemeyer H. 2014; 93-116.

11. Cousien A, Tran VC, Deuffic Burban S et al. Dynamic modeling of hepatitis C virus transmissioin among people who inject drugs: a methodological review. Jorunal of viral hepatitis, 2015, 22(3), 213-229

12. Nelson P, Mathers B, Cowie B, Hagan $\mathrm{H}$ et al. Global epidemiology of hepatitis B and hepatitis C in people who inject drugs: results of systematic reviews. Lancet, 2011, 378: 571-583. 
13. Passarino G, Ciccione G, Siragusa R, Tappero P, Mollo F. Histopathological findings in 851 autopsies of drug addicts, with toxicological and virological correlations. American Journal of Forensic Medicine\&Pathology. June 2005; 26: 2, 106-116

14. Ilic G, Karadzic R, Kostic Banovic L, Stioanovic J. Chronic Intravenous Heroin Abuse: Impact On The Liver. Medicine And Biology, 2005, 12(3): 150-153.

15. Alora PK, Fride E., Petito J. Morphine Induced Immune Alterations In Vivo. Cell Immunol 1990; 126:343-53

16. Hashigushi $\mathrm{Y}$, Molina Pe, Boxer R et al. Differential Responses Of Brain, Liver And Muscle Glycogen To Opiates And Surgical Stress. Surg Today. 1998; 28(4): 471-474.

17. Ali MA, Yeasmin F, Nag MN. Addiction and liver disease. Medicine today. 201325 (2):75-83.

18. Ilic G, Karadzic R, Kostic Banovic L, Stioanovic J. Influence Of Heroin On The Hepatocyte Glycogen Content. Acta Fac Med Naiss 2006; 23 (1): 9-12.

19. Ilic G, Kostic - Banovic L, Karadzic R, Stioanovic J. The Electron-Microscopic Findings On The Liver In Chronic Abuse Of Heroin. Medicine And Biology 2006, 13 (1): 6-10.

20. Ilic G, Kostic- Banovic L, Karadzic R, Stioanovic J. Ultrastuctural changes in the liver of intravenous heroin addicts. Bosnian Journal of Basic medical sciences, 2010; 10(1): 38-43.

21. Ilic G, Grigorievic J, Miloslevic I, Karadzic R. Evaluation of morphological changes of the liver caused by heroin abuse in forensic practice. Vojnosanit Pregl., 2010 May; 67(5): 403-410.

22. Ilic G, Karadzic R, Kostic Banovic L, Antovic A. Duration dependent effects of intravenous heroin intake on morphological changes in the liver. Rom J Leg Med, 2012, 20:13-18.

23. Prento P. Staining of macromolecules: possible mechanisms and examples. Biotech Histochem. , 2009, 84(4):139-58.

24. Reid PE, lagallo M, Nehr S, Jankunis M, Morrow P. Mechanism of connective tissue techniques. The effect of dye concentration and staining time on anionic dye procedures. Histochem. J. 1993; 25(11): 821-829.

25. Bezborodkina NN, Chestnova AY, Vorobev ML, Kudryavtsev BN. Glycogen content in hepatocytes is related with their size in normal rat liver but not in cirrhotic one. Cytometry $A$. 2016;89(4):357-64.

\section{Corresponding author:}

Dessislava Ljubomirova,

Clinic of Gastroenterology,

University Hospital "Dr G.Stranski",

5800, Pleven, Bulgaria

email: dr_lubomirova@abv.bg 